\title{
Diagnostic significance of CK19, TG, Ki67 and galectin-3 expression for papillary thyroid carcinoma in the northeastern region of China
}

\author{
Qingbin Song ${ }^{1 *}$, Deguang Wang ${ }^{2}$, Yi Lou ${ }^{3}$, Changsi Li ${ }^{4}$, Changqing Fang ${ }^{5}$, Xiangmin $\mathrm{He}^{6}$ and Jianhua $\mathrm{Li}^{5}$
}

\begin{abstract}
Background: To evaluate the expression and differential diagnostic significance of CK19, TG, Ki67 and galectin-3 in papillary thyroid carcinoma (PTC) (metastatic and non metastatic), follicular adenoma and nodular goiter in patients from the northeastern part of China.

Methods: 441 PTC specimens and 151 other benign thyroid specimens (97 cases of nodular goiter, 54 cases of nonmalignant follicular adenoma) were collected. Immunohistochemistry for CK19, TG, Ki67 and galectin-3 was performed.

Results: CK19, TG, Ki67 and galectin-3 expression was 96.37\% (425/441), 82.77\% (365/441), and 40.59\% (179/441), 96.82\% (427/441), respectively, for the PTC group and the expression of these markers in the benign thyroid lesions group was $25.83 \%$ (39/151), 79.47\% (120/151), and 37.09\% (56/151), 50.99\% (77/151), respectively. The expression of CK19 and galectin-3 in PTC was much higher than that in the nonmalignant group $(p<0.05)$. However, the expression of TG, Ki67 did not differ among these two groups ( $p>0.05$ ). The diagnostic efficiency of CK19 and galectin-3 for PTC was 96.37\% (537/592) and 84.63\% (501/592). CK19 and galectin-3 expression rate in PTC was higher than that in benign disease cases.

Conclusions: The diagnostic efficiency of CK19 for PTC was slightly better than galectin-3. The utilization of these markers combined with morphologic evaluation may be helpful in the differential diagnosis of papillary thyroid carcinoma in the northeastern region of China.
\end{abstract}

Keywords: Papillary thyroid carcinoma, CK19, TG, Ki67, galectin-3

\section{Background}

Thyroid cancer is the most common endocrine malignant tumor and encompass the most common well-differentiated papillary carcinoma ( $80 \%$ of all thyroid cancers) and follicular carcinoma (15\%), as well as poorly differentiated carcinoma $(<1 \%)$ and anaplastic carcinoma $(<2 \%)[1]$. PTC is the most common form of thyroid cancer, however, it is often difficult to differentiate PTC from benign papillary hyperplasia of the thyroid gland based on their morphology [2]. Some proteins' alteration was found in thyroid cancer, such as CK19,

\footnotetext{
* Correspondence: sqb1966@163.com

'Department of general surgery, The First affiliated hospital, China Medical University (Nanjing North Street), Shenyang (110001), China Full list of author information is available at the end of the article
}

TG, Ki67, Calcitonin, TTF-1, BRAF, RET, HBME-1, SERPINA1, TfR1/CD71, FHL1 and galectin-3 [3-12].

In the recent years, a large number of molecular alterations in thyroid cancer have been used in the distinction of malignant from benign thyroid lesions. These biomarkers, such as CK19, TG, Ki67, Calcitonin, TTF-1, BRAF, RET, HBME-1, and galectin-3, have been translated into clinical practice which offered significant improvement in the preoperative diagnosis of thyroid cancer [3-6,8,11,12]. Molecular markers used in the distinction of thyroid cancer from benign thyroid lesions in the First affiliated hospital of China Medical University between 2008-2011 were showed in table 1. Among these markers, galectin-3, TG, Ki67 and cytokeratin-19 (CK-19) have been most frequently used in thyroid pathology [13-16]. In this study, we assessed four
C Biomed Central 
Table 1 Molecular markers used in the distinction of malignant from benign thyroid lesions

\begin{tabular}{ll}
\hline Description & Gene symbol \\
\hline thyroid transcription factor-1 & TTF-1 \\
GALECTIN 3 & GAL3 \\
Calcitonin & CALCA \\
HEMATOPOIETIC PROGENITOR CELL ANTIGEN CD34 & CD34 \\
keratin, type I cytoskeletal 19 & CK19 \\
Thyroglobulin & Tg \\
KI67 Antigen & MKI67 \\
TUMOR PROTEIN p53 & P53 \\
\hline
\end{tabular}

immunohistochemical markers, CK19, TG, Ki67 and galectin-3, and evaluated their diagnostic significance for papillary thyroid carcinoma in the northeastern region of China.

\section{Materials and methods}

A total of 592 thyroid samples from the northeastern part of China collected by the Department of pathology in First affiliated hospital of China Medical University between 2008 and 2011 were used in this study. There were 441 cases in the PTC group, which included 110 men and 331 women (1:3.01), with an average age of 56 years (range 13-89 years). The diagnosis of papillary carcinomas were based on characteristic cytologic features, which includes nuclear irregularity (nuclear grooves, clearing, and increased size) and pseudoinclusions [12]. The nonmalignant group contained 151 cases (97 cases of nodular goiter, 54 cases of nonmalignant follicular adenoma) which included 38 men and 113 women (1:2.97), with an average age of 45 years (range 25-68 years). All resected specimens were fixed in 10\% neutral buffered formalin ( $\mathrm{pH} 7.4$ ), embedded in paraffin, cut into $5-\mu \mathrm{m}$ sections, and stained with hematoxylin and eosin (H\&E). Informed consent was obtained from all patients that donated their specimens, and all experiments were approved by the hospital's ethics committee.

\section{Reagents}

The antibodies included: CK19 (mouse monoclonal antihuman antibody sc-53258; 1:50; Santa cruz biotechnology, CA, USA); TG (mouse monoclonal antibody sc53543; 1:100; Santa cruz biotechnology, CA, USA); Ki67 (mouse monoclonal antibody sc-23900; 1:100; Santa cruz biotechnology, CA, USA) and galectin-3 (mouse monoclonal anti-human anti-body clone: 9 C4; 1:50; Beijing Zhong Shan Biotechnology, Beijing, China).

\section{Immunohistochemistry}

Immunostaining has been performed by using monoclonal antibodies for CK19, TG, Ki67 and galectin-3. After deparafinisation the sections were rehydrated. Endogenous peroxidase activity was blocked by $3 \%$ hydrogen peroxide. Antigen retrieval was performed in a microwave oven for $15 \mathrm{~min}$ in $10 \mathrm{nM}$ citrate buffer $\mathrm{pH} 6.0$ for all primary antibodies. The sections were incubated at room temperature for $2 \mathrm{~h}$ with primary monoclonal antibodies. After washing in phosphate-buffered saline, the tissues were incubated with a biotin-conjugated secondary antibody for $1 \mathrm{~h}$ at room temperature. The reactions became visible after immersion of diaminobenzidine tetrahydrochloride (DAB).

\section{Immunohistochemical Evaluation}

The cells were regarded as positive for these markers when immunoreactivity was clearly observed in their cell membrane and/or cytoplasm. For each antibody, immunoreactivity (no staining or weak staining less than $10 \%$ of the cells) was scored as negative and other immunoreactivity was scored as positive.

\section{Statistical Analysis}

Statistical analysis was performed using SPSS V.11.5. The $\mathrm{X}^{2}$ test and Fisher exact test were used for comparison of the immunohistochemistry results between the PTC and nonmalignant groups. Sensitivity (true positive/true positive + false negative), specificity (true negative/true negative + false positive), False negative rate (1-Sensitivity), False positive rate (1-specificity), and diagnostic accuracy (true positive + true negative/all positives + all negatives) of each marker were assessed in papillary thyroid carcinomas.

\section{Results}

\section{Immunohistochemistry results}

In order to evaluate the diagnostic significance of CK19, TG, Ki67 and galectin-3 expression in the distinction of PTC from benign thyroid lesions, we detected these markers expression by using immunohistochemistry. The result of immunohistochemistry was seen in Figure 1. As showed in Table 2, CK19, TG, Ki67 and galectin-3 expression was $96.37 \%$ (425/441), 82.77\% (365/441), and $40.59 \%$ (179/441), $96.82 \%$ (427/441), respectively, for the PTC group and the expression of these markers in the benign thyroid lesions group was 25.83\% (39/151), $79.47 \%$ (120/151), and 37.09\% (56/151), 50.99\% (77/ 151), respectively. The expression of CK19 and galectin3 in PTC was much higher than that in the nonmalignant group $(\mathrm{p}<0.05)$. However, the expression of TG, Ki67 did not differ among these two groups ( $p>0.05$ ).

Then we analyzed CK19 and Galectin-3 expression in PTC with or without lymphatic metastasis and different benign thyroid lesions. As showed in Table 3 and Figure 2, Galectin-3 positive rate in these four groups was $52.58 \%$ (nodular goiter), 48.15\% (follicular adenoma), 97.17\% (papillary thyroid carcinoma without lymphatic metastasis) and $96.37 \%$ (papillary thyroid carcinoma 


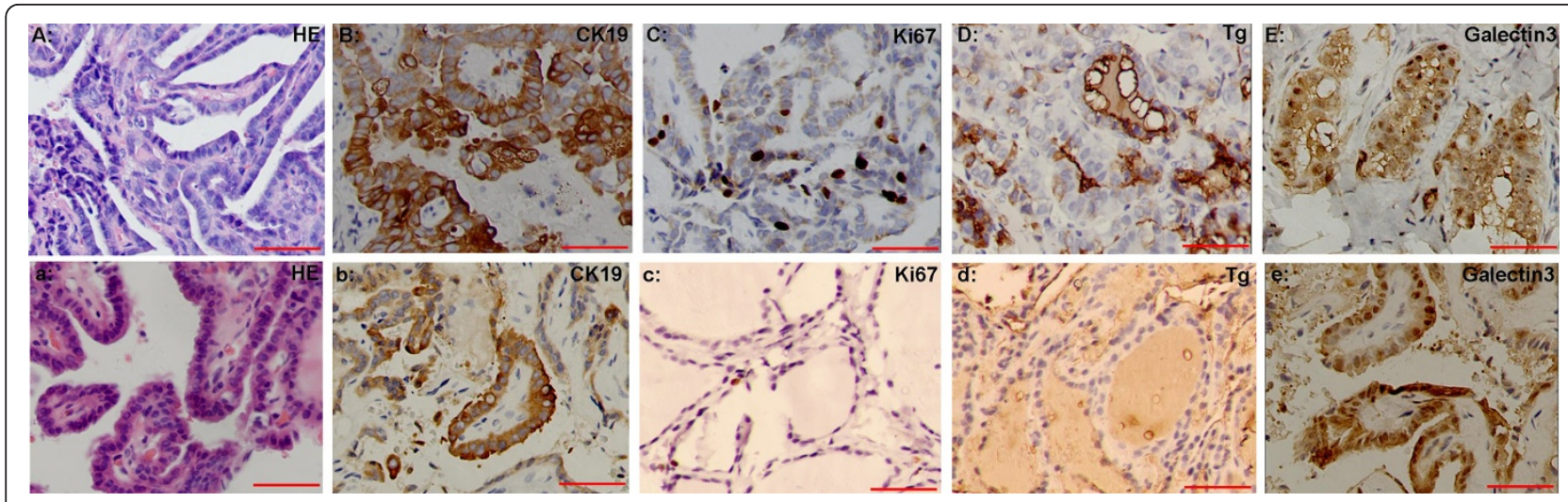

Figure 1 CK19, TG, Ki67 and galectin-3 immunoreactivity in PTC and nonmalignant thyroid lesion. A-E: HE, CK19, TG, Ki67 and galectin-3 staining in PTC; a-e: HE, CK19, TG, Ki67 and galectin-3 staining in nonmalignant thyroid lesion. Scale bar: $50 \mu m$.

with lymphatic metastasis), respectively. CK19 positive rate in these four groups was $26.80 \%$ (nodular goiter), 24.08\% (follicular adenoma), 99.20\% (papillary thyroid carcinoma without lymphatic metastasis) and $92.74 \%$ (papillary thyroid carcinoma with lymphatic metastasis), respectively. CK19 and Galectin-3 expression did not differ among nodular goiter and follicular adenoma or PTC with lymphatic metastasis and PTC without lymphatic metastasis. There was significant difference in CK19 and Galectin-3 expression between nodular goiter (or follicular adenoma) and PTC with lymphatic metastasis (or PTC without lymphatic metastasis), $\mathrm{P}<0.05$.

At last, diagnostics performance of CK19 in the distinction of PTC from benign thyroid lesions was compared with that of Galectin-3. As showed in Table 4, Diagnostic efficiency of CK19 (90.71\%) was slightly higher than that of Galectin-3(84.63\%) and the specificity and false positive rate (misdiagnosis rate) of CK19 was better than Galectin-3.

\section{Discussion}

Papillary carcinoma is the most common malignancy originating from the thyroid. Conventionally, discrimination

Table 2 Immunohistochemistry results in papillary thyroid carcinoma (PTC) and other nonmalignant thyroid lesions

\begin{tabular}{llcccc}
\hline & & $\begin{array}{c}\text { Nonmalignant lesions } \\
\mathbf{N}=\mathbf{1 5 1}\end{array}$ & $\begin{array}{c}\text { PTC } \\
\mathbf{N}=\mathbf{4 4 1}\end{array}$ & $\mathbf{X}^{\mathbf{2}}$ & $\mathbf{P}$ \\
\hline CK19 & + & $39(25.83)$ & $425(96.37)$ & 326.17 & $6.56 \mathrm{E}-73$ \\
& - & $112(74.17)$ & $16(3.63)$ & & \\
Tg & + & $120(79.47)$ & $365(82.77)$ & 0.62 & 0.43 \\
& - & $31(20.53)$ & $76(17.23)$ & & \\
\multirow{2}{*}{ Ki67 } & + & $56(37.09)$ & $179(40.59)$ & 0.44 & 0.51 \\
& - & $95(62.91)$ & $262(59.41)$ & & \\
\multirow{2}{*}{ Galectin } & + & $77(50.99)$ & $427(96.82)$ & 183.10 & $1.02 \mathrm{E}-41$ \\
& - & $74(49.01)$ & $14(3.18)$ & & \\
\hline
\end{tabular}

between benign and malignant thyroid nodules is attempted by fine needle aspiration biopsy (FNAB) followed by cytological assessment [1]. Despite many advances in the diagnosis and treatment of thyroid nodules and thyroid cancer, these methods have a well known low specificity [3,4]. The searching of the reliable and repeatable immunohistochemical markers in the distinction between benign thyroid nodules and papillary thyroid carcinoma is urgent. To date, many studies have tried to classify the different biomarkers of thyroid carcinoma on the basis of their gene expression profiles. Some proteins' alteration was found in thyroid cancer, such as CK19, TG, Ki67, Calcitonin, TTF-1, BRAF, RET, HBME1, SERPINA1, TfR1/CD71, FHL1 and galectin-3 [3-12]. Some of these proteins could be applicable to differentiate thyroid cancer from benign thyroid lesions in clinical practice. Molecular markers used in the distinction of

Table 3 Immunohistochemistry results of CK19 and Galectin-3 in papillary thyroid carcinoma (PTC) with or without lymphatic metastasis and other nonmalignant thyroid lesions

\begin{tabular}{|c|c|c|c|c|c|c|}
\hline & & & $\begin{array}{c}\text { nodular } \\
\text { goiter } \\
\mathrm{n}=97\end{array}$ & $\begin{array}{c}\text { Follicular } \\
\text { adenoma } \\
\mathrm{N}=54\end{array}$ & $\begin{array}{l}\mathrm{PTC}^{1} \\
\mathrm{~N}= \\
248\end{array}$ & $\begin{array}{l}\text { PTC }^{2} \\
N= \\
193\end{array}$ \\
\hline \multirow[t]{4}{*}{ CK19 } & + & Female & $21(21.65)$ & $10(18.52)$ & $\begin{array}{c}202 \\
(81.45)\end{array}$ & $\begin{array}{c}121 \\
(62.69)\end{array}$ \\
\hline & & Male & $5(5.15)$ & $3(5.56)$ & $\begin{array}{c}44 \\
(17.75)\end{array}$ & $\begin{array}{c}58 \\
(30.05)\end{array}$ \\
\hline & - & Female & $52(53.61)$ & $30(55.56)$ & $0(0.00)$ & $8(4.15)$ \\
\hline & & Male & 19(19.59) & $11(20.36)$ & $2(0.80)$ & $6(3.11)$ \\
\hline \multirow[t]{4}{*}{ Galectin } & + & Female & $37(38.15)$ & 19(35.19) & $\begin{array}{c}196 \\
(79.03)\end{array}$ & $\begin{array}{c}122 \\
(63.21)\end{array}$ \\
\hline & & Male & $14(14.43)$ & $7(12.96)$ & $\begin{array}{c}45 \\
(18.14)\end{array}$ & $\begin{array}{c}64 \\
(33.16)\end{array}$ \\
\hline & - & Female & $36(37.11)$ & 21(38.89) & $6(2.43)$ & $7(3.63)$ \\
\hline & & Male & $10(10.31)$ & $7(12.96)$ & $1(0.40)$ & $0(0.00)$ \\
\hline
\end{tabular}

PTC $^{1}$ : papillary thyroid carcinoma (PTC) without lymphatic metastasis PTC $^{2}$ : papillary thyroid carcinoma (PTC) with lymphatic metastasis 


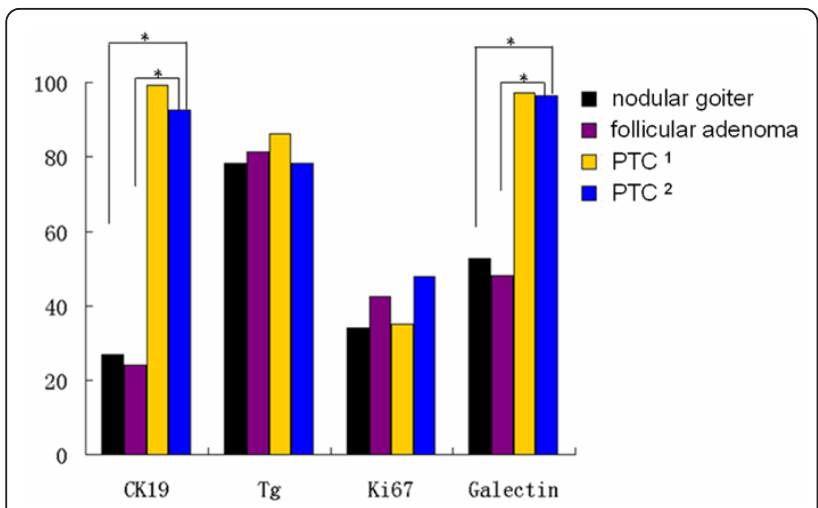

Figure 2 CK19, TG, Ki67 and galectin-3 positive rate in nodular goiter, follicular adenoma, papillary thyroid carcinoma without lymphatic metastasis and papillary thyroid carcinoma with lymphatic metastasis. PTC ${ }^{1}$ : papillary thyroid carcinoma (PTC) without lymphatic metastasis; PTC ${ }^{2}$ : papillary thyroid carcinoma (PTC) with lymphatic metastasis.

thyroid cancer from benign thyroid lesions in the First affiliated hospital of China Medical University between 2008-2011 were showed in table 1. In this study, we assessed four immunohistochemical markers, CK19, TG, Ki67 and galectin-3, and evaluated their diagnostic significance for papillary thyroid carcinoma in the northeastern region of China.

\section{Ki-67}

Cell proliferative activity is one of the important factors for assessing the biological behavior of carcinoma. At present, the most useful marker to evaluate cell proliferative activity is $\mathrm{Ki}-67$, which is expressed in all cells except those in the G0 phase [17]. Ki-67 has potential applications in differential diagnosis between malignant and benign lesions in human neoplasms. In thyroid neoplasms, Ki-67 expression has been investigated by several groups, but it has shown conflicting. Although some of the articles support strong expression in the malignant group [18]. Another support that there is no significant difference in the Ki-67 expression between thyroid carcinoma and adenoma [19]. In this study we found Ki-67 was expressed in $37.09 \%$ benign thyroid lesions (nodular goiter or follicular adenoma) and $40.59 \%$ PTC cases and the difference of positive rate between these two groups had no statistical significance.

Table 4 Diagnostics performance of CK19 and Galectin-3 in the distinction of PTC from benign thyroid lesions

\begin{tabular}{llllll}
\hline & SN & SP & FNR & FPR & DAC \\
\hline CK19 & $96.37 \%$ & $74.17 \%$ & $3.63 \%$ & $25.83 \%$ & $90.71 \%$ \\
Galectin-3 & $96.82 \%$ & $49.01 \%$ & $3.18 \%$ & $50.99 \%$ & $84.63 \%$ \\
\hline
\end{tabular}

SN; Sensitivity; SP: specificity; FNR: False negative rate; FPR: False positive rate; DAC: diagnostic accuracy
The results suggest Ki-67 is not a suitable biomarker used in the distinction of PTC from benign thyroid lesions in the northeastern region of China.

TG

Thyroglobulin $(\mathrm{Tg})$ is exclusively produced in thyroid follicular cells or by thyroid tumors of follicular cell origin. Measurement of the serum Tg level is used to monitor patients for residual or recurrent thyroid cancer [20]. However, studies on the expression of Tg in thyroid tissues were not common and Lazar et al found TG expression was decreased in thyroid carcinomas but was normal in the other tissues [21]. In this study we found Tg was expressed in $79.47 \%$ benign thyroid lesions (nodular goiter or follicular adenoma) and $82.77 \%$ PTC cases and the difference of positive rate between these two groups had no statistical significance. The results also suggest Tg is not a suitable biomarker used in the distinction of PTC from benign thyroid lesions in the northeastern region of China.

In this study, galectin-3 and CK19 protein were analyzed by immunohistochemical method in the thyroid tissues from 592 patients with histomorphological diagnosis of nodular goiter $(n=97)$, follicular adenoma $(n=54)$, papillary thyroid carcinoma without lymphatic metastasis $(\mathrm{n}=$ 248), and papillary thyroid carcinoma with lymphatic metastasis $(\mathrm{n}=93)$. The positive rates of Galectin-3 and CK19 in these four groups in the northeastern region of China were in complete agreement with Martins' results [22]. The difference of Galectin-3 and CK19 positive rate between PTC and benign lesions had statistical significance which suggests that the immunohistochemical study of Galectin-3 and CK19 may be potential markers for PTC.

\section{Galectin-3}

Galectin-3 is a protein of the lectin family that has been associated with neoplastic processes in various tissues [23]. In the thyroid, expression of this protein has been described in differentiated follicular cancer, suggesting that the immunohistochemical study of galectin-3 may be a potential marker of malignancy in thyroid neoplasms [3,12,22,24-27]. Galectin-3 positive rate in these four groups was $52.58 \%$ (nodular goiter), $48.15 \%$ (follicular adenoma), $97.17 \%$ (papillary thyroid carcinoma without lymphatic metastasis) and $96.37 \%$ (papillary thyroid carcinoma with lymphatic metastasis), respectively. In a study by Bartolazzi et al., the sensitivity and specificity of galectin-3 in thyroid carcinomas were $99 \%$ and $98 \%$, respectively [28]. In the present study, our finding about the expression of galectin-3 in thyroid carcinomas was less specificity (49.01\%). This may be partially due to the subjective criteria used in assessing positive expression or genetic heterogeneity of PTC in different ethnic group. 


\section{CK19}

CK19 (Keratin 19) is a member of the keratin family. The keratins are intermediate filament proteins responsible for the structural integrity of epithelial cells. CK-19 is strongly and diffusely expressed in papillary carcinoma, whereas it is usually absent or focally expressed in benign follicular nodules [29-31]. CK19 positive rate in these four groups was $26.80 \%$ (nodular goiter), $24.08 \%$ (follicular adenoma), $99.20 \%$ (papillary thyroid carcinoma without lymphatic metastasis) and $92.74 \%$ (papillary thyroid carcinoma with lymphatic metastasis), respectively. The role of CK-19 in the diagnosis of thyroid carcinoma is controversial [32]. Schelfhout et al. have found CK-19 expression in all tumor cells of papillary carcinomas, but it was absent or only focally present in follicular carcinomas and follicular adenomas [33]. In the current study, although we found CK-19 expression in follicular adenomas or nodular goiter but the CK-19 was the most sensitive $(96.37 \%)$ and specific $(74.17 \%)$ marker in papillary carcinomas. Diagnostic efficiency of CK19 (90.71\%) was slightly higher than that of Galectin-3(84.63\%) and the specificity and false positive rate (misdiagnosis rate) CK19 was better than Galectin-3.

In conclusion, we have demonstrated four markers expressed in papillary thyroid carcinomas and found $\mathrm{Ki}$ 67 and $\mathrm{Tg}$ were not suitable biomarkers used in the distinction of PTC from benign thyroid lesions in the northeastern region of China. The utility of galectin-3 and CK-19 may provide significant contributions in the differential diagnosis of malignant thyroid tumors. The utilization of these markers combined with morphologic evaluation may be helpful in the differential diagnosis of papillary thyroid carcinoma in the northeastern region of China.

\section{Acknowledgements \\ Project supported by Liaoning Provincial Natural Science Foundation of China (20102270, 20082077, 20082083). We would like to express our gratitude to all the subjects who participated in the study.}

\section{Author details \\ 'Department of general surgery, The First affiliated hospital, China Medical University (Nanjing North Street), Shenyang (110001), China. ${ }^{2}$ Department of Magnetic Resonance Imaging, No. 404 Hospital of People's Liberation Army (Baoquan Road), Weihai (264200), China. ${ }^{3}$ Department of genetics, China Medical University (North 2. Road), Shenyang (110001), China. ${ }^{4}$ Department of rehabilitation, The First affiliated hospital, China Medical University (Nanjing North Street), Shenyang (110001), China. ${ }^{5}$ Department of pathology, The First affiliated hospital, China Medical University (Nanjing North Street), Shenyang (110001), China. Department of pathology, China Medical University (North 2. Road), Shenyang (110001), China. ${ }^{6}$ Department of digestive medicine, The First affiliated hospital, China Medical University (Nanjing North Street), Shenyang (110001), China.}

\section{Authors' contributions}

QBS designed the study and wrote the protocol, YL, CSL, CQF and DGW performed research and wrote the first draft of the manuscript. $\mathrm{XMH}$ and JHL managed the Statistical Analysis. All authors read and approved the final manuscript.

\section{Competing interests}

The authors declare that they have no competing interests.

Received: 27 October 2011 Accepted: 21 December 2011

Published: 21 December 2011

\section{References}

1. Nikiforov YE: Thyroid tumors: classification and general considerations. In Diagnostic Pathology and Molecular Genetics of the Thyroid. Edited by: Nikiforov YE, Biddinger PW, Thompson LDR. Lippincott Williams 2009:94-102.

2. DeVita VT, Hellman JS, Rosenberg SA: Cancer: principles and practice of oncology. Lippincott Williams \& Wilkins 2008, 1674-1699.

3. Sethi K, Sarkar S, Das S, Mohanty B, Mandal M: Biomarkers for the diagnosis of thyroid cancer. J Exp Ther Oncol 2010, 8:341-352.

4. Kato MA, Fahey TJ: Molecular markers in thyroid cancer diagnostics. Surg Clin North Am 2009, 89:1139-1155.

5. Nikiforov YE: Molecular analysis of thyroid tumors. Mod Pathol Suppl 2011, 2:34-43.

6. Ito Y, Miyauchi A, Kakudo K, Hirokawa M, Kobayashi K, Miya A: Prognostic significance of ki-67 labeling index in papillary thyroid carcinoma. World J Surg 2010, 34:3015-21.

7. Vierlinger K, Mansfeld MH, Koperek O, Nöhammer C, Kaserer K, Leisch F; Identification of SERPINA1 as single marker for papillary thyroid carcinoma through microarray meta analysis and quantification of its discriminatory power in independent validation. BMC Med Genomics 2011, 6;4:30

8. Tan A, Etit D, Bayol U, Altinel D, Tan S: Comparison of proliferating cell nuclear antigen, thyroid transcription factor-1, Ki-67, p63, p53 and highmolecular weight cytokeratin expressions in papillary thyroid carcinoma, follicular carcinoma, and follicular adenoma. Ann Diagn Pathol 2011, 15:108-116.

9. Fryknäs M, Wickenberg-Bolin U, Göransson H, Gustafsson MG, Foukakis T, Lee JJ, Landegren U, Höög A, Larsson C, Grimelius L, Wallin G, Pettersson U, Isaksson A: Molecular markers for discrimination of benign and malignant follicular thyroid tumors. Tumour Biol 2006, 27:211-220.

10. Magro G, Cataldo I, Amico P, Torrisi A, Vecchio GM, Parenti R, Asioli S, Recupero D, D'Agata V, Mucignat MT, Perris R: Aberrant expression of TfR1/CD71 in thyroid carcinomas identifies a novel potential diagnostic marker and therapeutic target. Thyroid 2011, 21:267-277.

11. Chiu CG, Strugnell SS, Griffith OL, Jones SJ, Gown AM, Walker B, Nabi IR, Wiseman SM: Diagnostic utility of galectin-3 in thyroid cancer. Am J Pathol 2010, 176:2067-2081.

12. Barut F, Onak Kandemir N, Bektas S, Bahadir B, Keser S, Ozdamar SO: Universal markers of thyroid malignancies: galectin-3, HBME-1, and cytokeratin-19. Endocr Pathol 2010, 21:80-89.

13. Park YJ, Kwak SH, Kim DC, Kim H, Choe G, Park do J, Jang HC, Park SH, Cho BY, Park SY: Diagnostic value of galectin-3, HBME-1, cytokeratin 19, high molecular weight cytokeratin, cyclin D1 and p27 (kip1) in the differential diagnosis of thyroid nodules. J Korean Med Sci 2007, 22:621-628.

14. El Demellawy D, Nasr A, Alowami S: Application of CD56, P63 and CK19 immunohistochemistry in the diagnosis of papillary carcinoma of the thyroid. Diagn Pathol 2008, 3:5

15. Prasad ML, Pellegata NS, Huang Y, Nagaraja HN, de la Chapelle A, Kloos RT: Galectin-3, fibronectin-1, CITED-1, HBME-1 and cytokeratin-19 immunohistochemistry is useful for the differential diagnosis of thyroid tumors. Mod Pathol 2005, 18:48-57.

16. de Matos PS, Ferreira AP, de Oliveira Facuri F, Assumpção LV, Metze K, Ward LS: Usefulness of HBME-1, cytokeratin-19 and galectin-3 immunostaining in the diagnosis of thyroid malignancy. Histopathology 2005, 47:391-401.

17. Cattoretti G, Becker MH, Key G, Duchrow M, Schlüter C, Galle J, Gerdes J: Monoclonal antibodies against recombinant parts of the Ki-67 antigen (MIB 1 and MIB 3) detect proliferating cells in microwave-processed for malin-fixed paraffin sections. J Pathol 1992, 168:357-363.

18. Saiz AD, Olvera M, Rezk S, Florentine BA, McCourty A, Brynes RK: Immunohistochemical expression of cyclin D1, E2F-1, and Ki-67 in benign and malignant thyroid lesions. J Pathol 2002, 198:157-162.

19. Liang HS, Zhong YH, Luo ZJ, Huang Y, Lin HD, Luo M, S-Zhan Su HX, Zhou SB, Xie KQ: Comparative analysis of protein expression in 
differentiated thyroid tumours: a multicentre study. J Int Med Res 2009, 37:927-938.

20. Carpi A, Mechanick JI, Saussez S, Nicolini A: Thyroid tumor marker genomics and proteomics: diagnostic and clinical implications. J Cell Physiol 2010, 224:612-619.

21. Lazar V, Bidart JM, Caillou B, Mahé C, Lacroix L, Filetti S, Schlumberger M: Expression of the $\mathrm{Na}+/ \mathrm{l}$ - symporter gene in human thyroid tumors: a comparison study with other thyroid-specific genes. J Clin Endocrinol Metab 1999, 84:3228-3234.

22. Martins L, Matsuo SE, Ebina KN, Kulcsar MA, Friguglietti CU, Kimura ET: Galectin-3 messenger ribonucleic acid and protein are expressed in benign thyroid tumors. J Clin Endocrinol Metab 2002, 87:4806-4810.

23. Raimond J, Zimonjic DB, Mignon C, Mattei M, Popescu NC, Monsigny M, Legrand A: Mapping of the galectin-3 gene (LGALS3) to human chromosome 14 at region 14q21-22. Mamm Genome 1997, 8:706-707.

24. Türköz HK, Oksüz H, Yurdakul Z, Ozcan D: Galectin-3 expression in tumor progression and metastasis of papillary thyroid carcinoma. Endocr Pathol 2008, 19:92-96.

25. Orlandi F, Saggiorato E, Pivano G, Puligheddu B, Termine A, Cappia S, De Giuli P, Angeli A: Galectin-3 is a presurgical marker of human thyroid carcinoma. Cancer Res 1998, 58:3015-3020.

26. Kawachi K, Matsushita Y, Yonezawa S, Nakano S, Shirao K, Natsugoe S, Sueyoshi K, Aikou T, Sato E: Galectin-3 expression in various thyroid neoplasms and its possible role in metastasis formation. Hum Pathol 2000, 31:428-433.

27. Kovàcs RB, Földes J, Winkler G, Bodó M, Sápi Z: The investigation of galectin-3 in diseases of thyroid gland. Eur J Endocrinol 2003, 149:449-453.

28. Bartolazzi A, Gasbarri A, Papotti M, Bussolati G, Lucante T, Khan A, Inohara H, Marandino F, Orlandi F, Nardi F, Vecchione A, Tecce R, Larsson O: Application of an immunodiagnostic method for improving preoperative diagnosis of nodular thyroid lesions. Lancet 2001, 357:1644-1650.

29. Erkiliç S, Aydin A, Koçer NE: Diagnostic utility of cytokeratin 19 expression in multinodular goiter with papillary areas and papillary carcinoma of thyroid. Endocr Pathol 2002, 13:207-211.

30. Fonseca E, Nesland JM, Höie J, Sobrinho-Simões M: Pattern of expression of intermediate cytokeratin filaments in the thyroid gland: an immunohistochemical study of simple and stratified epithelial-type cytokeratins. Virchows Arch 1997, 430:239-245.

31. Prasad ML, Huang Y, Pellegata NS, de la Chapelle A, Kloos RT: Hashimoto's thyroiditis with papillary thyroid carcinoma (PTC) - like nuclear alterations expresses molecular markers of PTC. Histopathology 2004, 45:39-46.

32. Rossi ED, Raffaelli M, Mule' A, Miraglia A, Lombardi CP, Vecchio FM, Fadda G: Simultaneous immunohistochemical expression of HBME-1 and galectin-3 differentiates papillary carcinomas from hyperfunctioning lesions of the thyroid. Histopathology 2006, 48:795-800.

33. Schelfhout LJ, Van Muijen GN, Fleuren GJ: Expression of keratin 19 distinguishes papillary thyroid carcinoma from follicular carcinomas and follicular thyroid adenoma. Am J Clin Pathol 1989, 92:654-658.

doi:10.1186/1746-1596-6-126

Cite this article as: Song et al:: Diagnostic significance of CK19, TG, Ki67 and galectin-3 expression for papillary thyroid carcinoma in the northeastern region of China. Diagnostic Pathology 2011 6:126.

\section{Submit your next manuscript to BioMed Central and take full advantage of:}

- Convenient online submission

- Thorough peer review

- No space constraints or color figure charges

- Immediate publication on acceptance

- Inclusion in PubMed, CAS, Scopus and Google Scholar

- Research which is freely available for redistribution

Submit your manuscript at www.biomedcentral.com/submit
C Biomed Central 